\title{
A Dead Time Compensation Algorithm of Independent Multi-Phase PMSM with Three- Dimensional Space Vector Control
}

\author{
Ouk-Sang Park ${ }^{*}$, Je-Wook Park ${ }^{* *}$, Chae-Bong Bae ${ }^{* * *}$, and Jang-Mok Kim ${ }^{\dagger}$ \\ *STX Engine, Changwon, Korea \\ ${ }^{* * \dagger}$ Dept. of Electrical Eng., Pusan National University, Busan, Korea \\ ${ }^{* * *}$ Dept. of LV drive, LSIS, Busan, Korea
}

\begin{abstract}
This paper proposes a new dead time compensation method of independent six-phase permanent magnet synchronous motors (IS-PMSM). The current of the independent phase machines contains odd-numbered harmonics because of the dead time and the nonlinear characteristics of the switching devices. By using the d-q-n three-dimensional vector analysis, these harmonics can be extracted at the $\mathrm{n}$-axis current. Thus, the current distortion can be compensated by controlling the n-axis current of the IS-PMSM to zero. The proposed method is simple and can be easily implemented without additional hardware setup. The validity of the proposed compensation method is verified with simulations and several experiments.
\end{abstract}

Key words: Current harmonics, Dead time, Independent phase, IS-PMSM, Vector control

\section{INTRODUCTION}

Multi-phase permanent magnet synchronous motors (M-PMSM) are useful for high power applications such as electrical propulsion of ships, locomotive tractions or electric vehicle applications, because it has many advantages over conventional 3-phases such as reducing torque ripple, lowering the DC link current harmonics, improving reliability and decreasing the current stress of switching devices [1], [2]. In multi-phase drives, it is possible to implement the low power switching devices for the high power applications since the controlled power is divided over several inverter legs [3], [4]. Although failure of any single-phase drive unit degrades the control performance of the IM-PMSM, the urgency of immediate repairs is reduced since the system shutdown is not required [5].

In the voltage source inverter (VSI), the current harmonics occurs due to the dead-time and nonlinear characteristics of the switching devices. The compensation methods of the dead time

Manuscript received Jul. 24, 2012; revised Oct. 24, 2012

Recommended for publication by Associate Editor Sanjeet K. Dwivedi.

${ }^{\dagger}$ Corresponding Author: jmok@pusan.ac.kr

Tel: +82-51-510-2366, Fax: +82-51-513-0212, Pusan Nat'1 University

* STX Engine, Changwon, Korea

** Dept. of Electrical Eng., Pusan National University, Busan, Korea

${ }^{* * *}$ Dept. of LV drive, LSIS, Busan, Korea effects for the Y-connected 3-phase machine have already been suggested in many technical literatures [6]-[17]. The average value of the lost voltage calculation [6], [7], the PWM pulse based method [8], the voltage feed forward method [9]-[13], the phase angle calculation method [14], the disturbance observer method [15], [16], and the support vector regression (SVR) method [17] are the main categories of the conventional dead time compensation methods. However, these methods are based on the Y-connected three-phase machine and have drawbacks such as parameter dependency and complexity.

This paper proposes the vector control method of the independent six-phase permanent magnet synchronous motor (IS-PMSM) based on a multiple $d-q-n$ axis analysis. Moreover, a new dead-time compensation method of the IS-PMSM is also proposed to eliminate the current harmonics due to the dead time and nonlinear characteristics of the switching devices. The simulation and the experimental results are shown to validate the proposed method.

\section{REVIEW OF DEAD TIME COMPENSATION METHODS}

Dead time compensation methods have been studied in many literatures. The main category of this topic can be 
classified as follows.

\section{A. Open Loop Methods}

In most cases, the open loop methods are based on the average value theory. The switching leg time is averaged over an entire cycle and added to the voltage reference [6], [7]. A pulse-based method [8] compensates the dead time for each PWM pulse. These methods are dependent on the direction of the phase current. In [9]-[13], the compensation voltage is fed to the reference voltage in order to generate a modified voltage. The compensation voltage is calculated by considering dead time, switching period, current command and DC link voltage. Since the voltage drop of switching devices and diodes is varied with operating conditions such as motor speed, the phase currents, and DC-link voltages, it is difficult to compensate the dead-time accurately in all operating ranges with these open loop methods.

\section{B. Closed Loop Methods}

The closed loop methods are proposed in [14]-[17]. The method in [14] needs the additional computational burden to determine the phase angle of currents and set up a lookup table. These problems can be solved by using a disturbance observer as shown in [15] and [16]. Therefore, it is necessary to tune parameters such as observer gains and load conditions. In [17], this method is based on an emerging learning technique called support vector regression (SVR). It is difficult to implement the SVR model method because it requires some parameters, online computation and extra memory to construct the regression function.

\section{MODELING OF THE IS-PMSM}

The IS-PMSM has six stator windings spatially shifted by $60^{\circ}$ electrical degrees with virtual neutral points as shown in Fig. 1.

The voltage equation of the IS-PMSM can be expressed as $v_{x}=A i_{x}+B \frac{d}{d t} i_{x}+e_{x}$

$A=\left[\begin{array}{llllll}R & 0 & 0 & 0 & 0 & 0 \\ 0 & R & 0 & 0 & 0 & 0 \\ 0 & 0 & R & 0 & 0 & 0 \\ 0 & 0 & 0 & R & 0 & 0 \\ 0 & 0 & 0 & 0 & R & 0 \\ 0 & 0 & 0 & 0 & 0 & R\end{array}\right] \quad B=\left[\begin{array}{cccccc}L & 0 & 0 & 0 & 0 & 0 \\ 0 & L & 0 & 0 & 0 & 0 \\ 0 & 0 & L & 0 & 0 & 0 \\ 0 & 0 & 0 & L & 0 & 0 \\ 0 & 0 & 0 & 0 & L & 0 \\ 0 & 0 & 0 & 0 & 0 & L\end{array}\right]$

where

$x$ : specific phase

$e_{x}$ : back EMF of each phase

$i_{x}$ : current of each phase

$R$ : stator resistance of each phase

$L: L_{s}-L_{m}$

$L_{s}$ : self inductance of each phase, $L_{m}$ : mutual inductance

The output torque of the IS-PMSM can be expressed as (2).

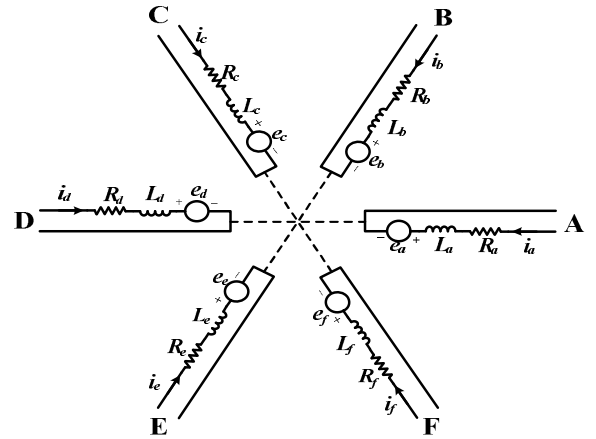

Fig. 1. Equivalent circuit of IS-PMSM.

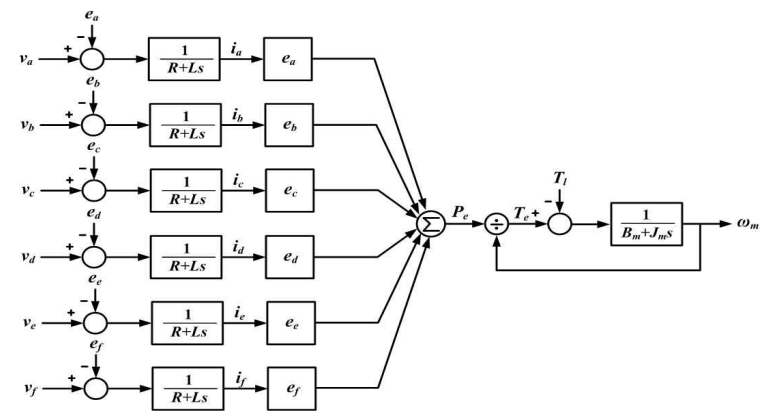

Fig. 2. Block diagram of IS-PMSM model.

$$
T_{e}=\frac{P_{e}}{\omega_{m}}=\frac{e_{a} i_{a}+e_{b} i_{b}+e_{c} i_{c}+e_{d} i_{d}+e_{e} i_{e}+e_{f} i_{f}}{\omega_{m}}=\frac{6 E_{s} I_{s}}{\omega_{m}}(2)
$$

where $P_{e}, E_{s} I_{s}$ and $\omega_{m}$ are the electrical power, RMS back-EMFs, RMS phase currents and mechanical angular speed of the rotor, respectively.

The torque equation of the rotational motion can be expressed as

$$
T_{e}=J_{m} \frac{d \omega_{m}}{d t}+B_{m} \omega_{m}+T_{L}
$$

where $J_{m}, B_{m}$ and $T_{L}$ are the inertia of the rotor, friction coefficient and load torque, respectively.

The mathematical model of the IS-PMSM is shown in Fig. 2.

The six-phase space vector can be equivalently represented by three-dimensional (3-D) complex space vector. The $d$-axis and $q$-axis can be expressed as

$$
\begin{aligned}
f_{s} & =\frac{1}{3}\left(a^{0} f_{a}+a^{1} f_{b}+a^{2} f_{c}+a^{3} f_{d}+a^{4} f_{e}+a^{5} f_{f}\right) \\
& =f_{d}^{s}+j f_{q}^{s}=f_{d q}^{s}
\end{aligned}
$$

where $a=e^{j \frac{\pi}{3}}$

Since the A, C, E phase and D, F, B phase are spatially shifted by $180^{\circ}$, the zero-sequence of the six-phases can be expressed as

$$
f_{n}=\frac{1}{6}\left(f_{a}-f_{b}+f_{c}-f_{d}+f_{e}-f_{f}\right)
$$


TABLE I

THE WHOLE SWITCHING VECTOR OF IS-PMSM

\begin{tabular}{|c|c|c|c|c|c|c|c|c|c|c|c|c|c|c|c|}
\hline & \multicolumn{6}{|c|}{ Switch combinations } & \multicolumn{6}{|c|}{ Phase voltage } & \multicolumn{3}{|c|}{$\begin{array}{c}\text { Space vector } \\
(\mathbf{K}=\mathbf{D}+\mathbf{j Q})\end{array}$} \\
\hline & $S_{a}$ & $S_{a}$ & $S_{a}$ & $S_{a}$ & $S_{a}$ & $S_{a}$ & $V_{a}$ & $V_{a}$ & $V_{a}$ & $V_{a}$ & $V_{a}$ & $V_{a}$ & $\mathbf{D}$ & $\mathbf{Q}$ & $\mathbf{K}$ \\
\hline 1 & $\mathbf{0}$ & $\mathbf{0}$ & $\mathbf{0}$ & $\mathbf{0}$ & $\mathbf{0}$ & $\mathbf{0}$ & $\mathbf{0}$ & $\mathbf{0}$ & $\mathbf{0}$ & $\mathbf{0}$ & $\mathbf{0}$ & $\mathbf{0}$ & $\mathbf{0}$ & $\mathbf{0}$ & $\mathbf{0}$ \\
\hline 2 & $\mathbf{1}$ & $\mathbf{0}$ & $\mathbf{0}$ & $\mathbf{0}$ & $\mathbf{0}$ & $\mathbf{0}$ & $\mathbf{V}$ & $\mathbf{0}$ & $\mathbf{0}$ & $\mathbf{0}$ & $\mathbf{0}$ & $\mathbf{0}$ & $1 / 3 V$ & $\mathbf{0}$ & $1 / 3 V \angle 0^{\circ}$ \\
\hline 3 & -1 & $\mathbf{0}$ & $\mathbf{0}$ & $\mathbf{0}$ & $\mathbf{0}$ & $\mathbf{0}$ & $-\mathrm{V}$ & $\mathbf{0}$ & $\mathbf{0}$ & $\mathbf{0}$ & $\mathbf{0}$ & $\mathbf{0}$ & $-1 / 3 V$ & $\mathbf{0}$ & $1 / 3 V \angle 180^{\circ}$ \\
\hline 377 & 1 & 1 & 1 & -1 & -1 & 1 & $\mathbf{V}$ & $\mathbf{V}$ & $\mathbf{V}$ & $-\mathrm{V}$ & $-\mathrm{V}$ & $\mathbf{V}$ & $\mathbf{0}$ & $-2 \sqrt{3} / 3 V$ & $1 / 3 V \angle 180^{\circ}$ \\
\hline 378 & 1 & 1 & 1 & -1 & -1 & -1 & $\mathbf{V}$ & $\mathbf{V}$ & $\mathbf{V}$ & $-\mathrm{V}$ & $-\mathrm{V}$ & $\mathbf{V}$ & $-2 / 3 V$ & $-2 \sqrt{3} / 3 V$ & $4 / 3 V \angle 120^{\circ}$ \\
\hline 379 & 1 & 1 & -1 & $\mathbf{0}$ & 0 & 0 & $\mathbf{V}$ & $\mathbf{V}$ & $-\mathrm{V}$ & 0 & $\mathbf{0}$ & 0 & $1 / 3 V$ & $\sqrt{3} / 3 V$ & $2 / 3 V \angle 60^{\circ}$ \\
\hline 727 & 0 & -1 & -1 & -1 & -1 & -1 & $\mathbf{0}$ & $-\mathrm{V}$ & $-V$ & $-\mathrm{V}$ & $-\mathrm{V}$ & $-\mathrm{V}$ & $1 / 3 V$ & $\mathbf{0}$ & $1 / 3 V \angle 0^{\circ}$ \\
\hline 728 & 1 & -1 & -1 & -1 & -1 & -1 & $\mathbf{V}$ & $-V$ & $-V$ & $-V$ & $-\mathrm{V}$ & $-\mathrm{V}$ & $1 / 3 V$ & $\mathbf{0}$ & $1 / 3 V \angle 180^{\circ}$ \\
\hline 729 & -1 & -1 & -1 & -1 & -1 & -1 & $-V$ & $-\mathrm{V}$ & $-\mathrm{V}$ & $-\mathrm{V}$ & $-\mathrm{V}$ & $-\mathrm{V}$ & 0 & $\mathbf{0}$ & $\mathbf{0}$ \\
\hline
\end{tabular}

TABLE II

ACTIVE AND ZERO VOLTAGE VECTOR OF IS-PMSM

\begin{tabular}{|c|c|c|c|c|c|c|c|c|c|c|c|c|c|c|c|}
\hline & \multicolumn{6}{|c|}{ Switch combinations } & \multicolumn{6}{|c|}{ Phase voltage } & \multicolumn{3}{|c|}{$\begin{array}{c}\text { Space vector } \\
(\mathrm{K}=\mathrm{D}+\mathrm{j} Q)\end{array}$} \\
\hline & $S_{a}$ & $S_{a}$ & $S_{a}$ & $S_{a}$ & $S_{a}$ & $S_{a}$ & $V_{a}$ & $V_{a}$ & $V_{a}$ & $V_{a}$ & $V_{a}$ & $V_{a}$ & D & Q & $\mathbf{K}$ \\
\hline $\mathbf{0}$ & 0 & 0 & $\mathbf{0}$ & $\mathbf{0}$ & $\mathbf{0}$ & $\mathbf{0}$ & $\mathbf{0}$ & $\mathbf{0}$ & $\mathbf{0}$ & $\mathbf{0}$ & 0 & $\mathbf{0}$ & $\mathbf{0}$ & $\mathbf{0}$ & $\mathbf{0}$ \\
\hline 1 & 1 & 1 & -1 & -1 & -1 & 1 & $\mathbf{V}$ & V & $-V$ & $-V$ & $-V$ & V & $4 / 3 V$ & 0 & $4 / 3 V \angle 0^{\circ}$ \\
\hline 2 & 1 & 1 & 1 & -1 & -1 & -1 & V & V & V & $-V$ & $-V$ & $-V$ & $2 / 3 V$ & $2 \sqrt{3} / 3 V$ & $4 / 3 V \angle 60^{\circ}$ \\
\hline 3 & -1 & 1 & 1 & 1 & -1 & -1 & $-\mathrm{V}$ & V & V & V & $-\mathrm{V}$ & $-V$ & $-2 / 3 V$ & $2 \sqrt{3} / 3 V$ & $4 / 3 V \angle 120^{\circ}$ \\
\hline 4 & -1 & -1 & 1 & 1 & 1 & -1 & $-V$ & $-V$ & V & V & V & $-V$ & $-4 / 3 V$ & 0 & $4 / 3 V \angle 180^{\circ}$ \\
\hline 5 & -1 & -1 & -1 & 1 & 1 & 1 & $-V$ & $-V$ & $-V$ & V & V & V & $-2 / 3 V$ & $-2 \sqrt{3} / 3 V$ & $4 / 3 V \angle 240^{\circ}$ \\
\hline 6 & 1 & -1 & -1 & -1 & 1 & 1 & V & $-V$ & $-V$ & $-V$ & V & V & $2 / 3 V$ & $-2 \sqrt{3} / 3 \mathrm{~V}$ & $4 / 3 V \angle 300^{\circ}$ \\
\hline 7 & 1 & 1 & 1 & 1 & 1 & 1 & 0 & 0 & 0 & 0 & 0 & 0 & 0 & 0 & 0 \\
\hline
\end{tabular}

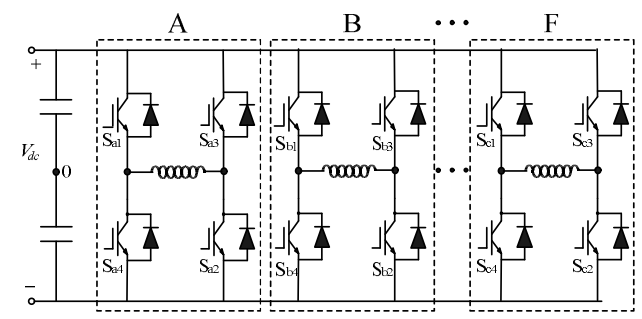

Fig. 3. Six separated H-bridge inverter for IS-PMSM.

Unlike the Y-connected machine, the independent phase machine does not have any neutral point. Thus, the IS-PMSM has $(6 n \pm 3)$ th harmonics which are in-phase with each phase
[18], [19]. Therefore, n-axis current is not always zero. The n-axis current is loss element and is not related to the torque of the IS-PMSM.

\section{PWM SCHEME OF THE IS-PMSM}

To drive the IS-PMSM, six separated H-bridge inverters are composed as shown in Fig. 3.

The space vector PWM (SVPWM) technique is widely used to control three-phase motors [20], [21]. In the H-bridge inverter, two PWM signals of each pole are complementary as described in (6) and the switching function can be expressed as (7). 


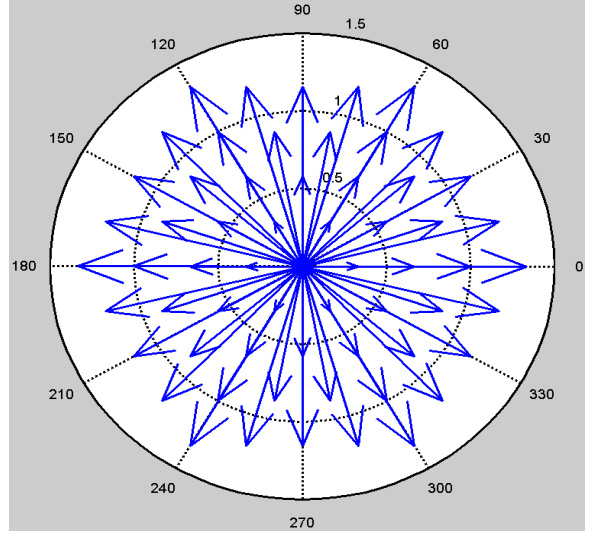

Fig. 4. The whole switching vectors of IS-PMSM.

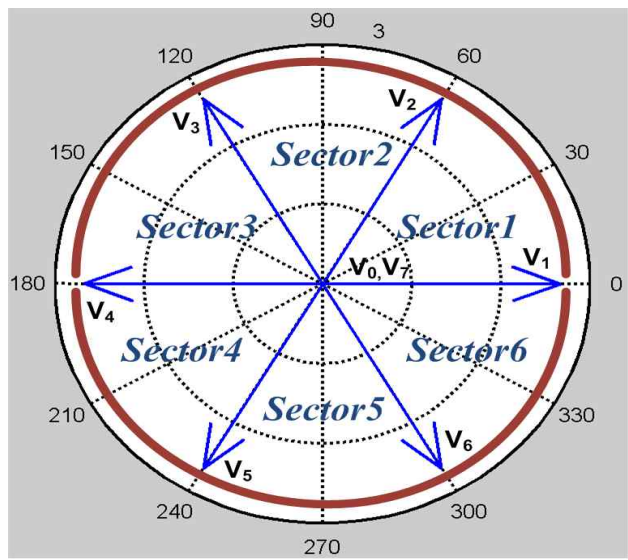

Fig. 5. Active and zero voltage vector of IS-PMSM.

$$
\begin{aligned}
& S_{1}=\bar{S}_{4} \\
& S_{2}=\bar{S}_{3} \\
& S_{H B}=\left(\frac{S_{1}-S_{4}}{2}\right)-\left(\frac{S_{3}-S_{2}}{2}\right)=S_{1}-S_{3} \\
& S_{H B} \in(1,0,-1)
\end{aligned}
$$

With six H-bridge inverters, $3^{6}=729$ voltage vector combinations can be made as shown in Table I and Fig. 4.

Among the whole switching vectors, 6 active voltage vectors and 2 zero voltage vectors can be obtained by removing voltage vectors which are smaller than $(4 / 3) V_{d c}$ or same direction vectors, as shown in Table II and Fig. 5.

However, it is difficult to implement SVPWM to drive the IS-PMSM with H-bridge inverters, because the discontinuous PWM signals are required during one switching period as shown in Fig. 6.

Hence, in this paper, the unipolar SPWM is used to control the IS-PMSM. In case of Y-connected machines, the voltage utility factor of SPWM is $61.2 \%$ of the DC link voltage and this value is smaller than $70.7 \%$ of SVPWM in the linear modulation range [20]. On the other hand, in case of IS-PMSM, the utility factor of SPWM is $70.7 \%$, because the maximum phase voltage of the H-bridge inverter is $V_{d c}$.

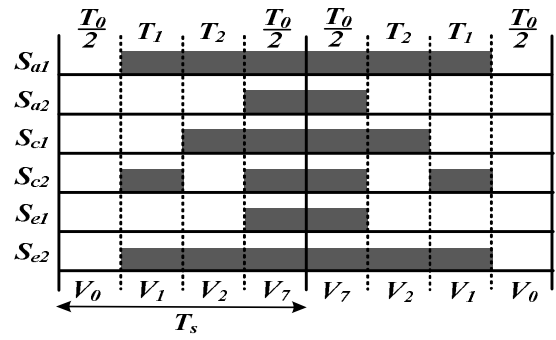

(a)

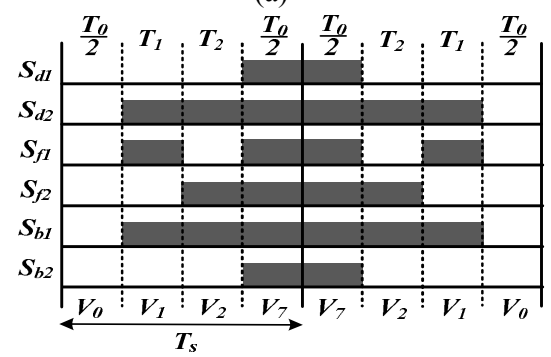

(b)

Fig. 6. PWM signals when the voltage vector is located between $0^{\circ}$ to $60^{\circ}$. (a) Phase A, C and E. (b) Phase D, F and B.

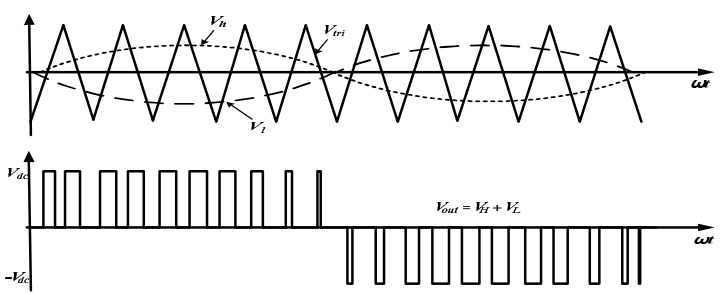

Fig. 7. Unipolar SPWM and the output voltage of the H-bridge inverter.

Fig. 7 shows the unipolar PWM of the H-bridge inverters. Since the frequency of the output voltage is twice the carrier frequency, total harmonic distortion (THD), iron loss and the current pulsation are lower than the bipolar SPWM [22].

\section{ANALYSIS OF THE DEAD TIME EFFECT}

The dead-time and the nonlinear characteristics of the switching devices cause the voltage distortion of the PWM inverter [21]. It is convenient to analyze the dead-time effects from one phase leg of the inverter and extend the results to the other phase legs. Fig. 8 shows the average voltage distortion of the H-bridge inverter based on the dead time (turn-on/off delay time of the switching devices).

If $S_{1}$ is turned off, the output voltage error occurs during the turn off time $T_{\text {off }}$. If $\mathrm{S}_{4}$ is turned on, the output voltage occurs during the dead time $T_{d}$ and the turn on time $T_{o n}$. Therefore, the voltage error can be expressed as

$$
\begin{gathered}
\Delta V=\frac{-T_{d}-T_{o n}+T_{o f f}}{T_{s}} V_{d c} \quad(i>0) \\
\Delta V=\frac{T_{d}+T_{o n}-T_{o f f}}{T_{s}} V_{d c} \quad(i<0)
\end{gathered}
$$

where $T_{s}$ is the switching period of the H-bridge inverter. 


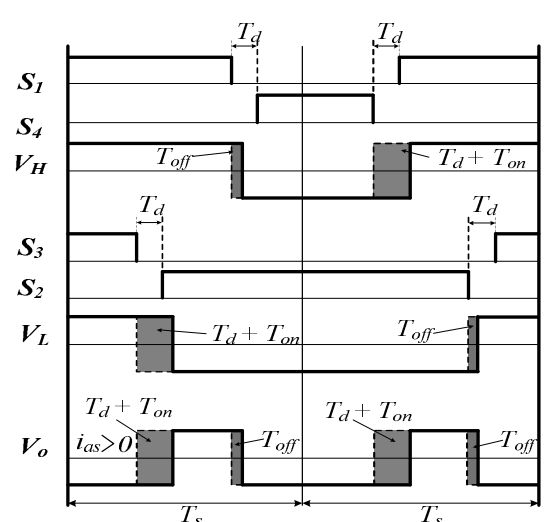

Fig. 8. Switching patterns and output voltages of the H-bridge inverter.

Therefore, the average voltage error of each phase can be expressed as

$$
\begin{aligned}
& \Delta V_{a s}=\frac{-T_{d}-T_{o n}+T_{o f f}}{T_{s}} V_{d c}\left\{\operatorname{sign}\left(i_{a s}\right)\right\} \\
& \Delta V_{b s}=\frac{-T_{d}-T_{o n}+T_{o f f}}{T_{s}} V_{d c}\left\{\operatorname{sign}\left(i_{b s}\right)\right\} \\
& \Delta V_{c s}=\frac{-T_{d}-T_{o n}+T_{o f f}}{T_{s}} V_{d c}\left\{\operatorname{sign}\left(i_{c s}\right)\right\} \\
& \Delta V_{d s}=\frac{-T_{d}-T_{o n}+T_{o f f}}{T_{s}} V_{d c}\left\{\operatorname{sign}\left(i_{d s}\right)\right\} \\
& \Delta V_{e s}=\frac{-T_{d}-T_{o n}+T_{o f f}}{T_{s}} V_{d c}\left\{\operatorname{sign}\left(i_{e s}\right)\right\} \\
& \Delta V_{f s}=\frac{-T_{d}-T_{o n}+T_{o f f}}{T_{s}} V_{d c}\left\{\operatorname{sign}\left(i_{f s}\right)\right\}
\end{aligned}
$$

Fig. 9 shows the phase currents and the voltage errors of the IS-PMSM. The voltage errors of each phase of the IS-PMSM can be represented in the frequency domain by using Fast Fourier Transform (FFT) as shown below:

$\Delta V_{x}=\frac{4}{\pi} \Delta V\left\{\sin \omega t+\frac{1}{3} \sin 3 \omega t+\frac{1}{5} \sin 5 \omega t+\frac{1}{7} \sin 7 \omega t+\cdots\right\}$

From (11), the current ripple based on the load impedance $Z_{L}\left(n \omega_{m}\right)$ and the load impedance angle $\Phi_{n}$ can be expressed as

$$
\Delta i_{x}=\frac{4}{\pi} \Delta V\left\{\begin{array}{l}
\frac{1}{Z_{L}(\omega)} \sin \left(\omega t-\phi_{1}\right)+\frac{1}{3 Z_{L}(3 \omega)} \sin 3\left(\omega t-\phi_{3}\right) \\
+\frac{1}{5 Z_{L}(5 \omega)} \sin 5\left(\omega t-\phi_{5}\right)+\frac{1}{7 Z_{L}(7 \omega)} \sin 7\left(\omega t-\phi_{7}\right)+\cdots
\end{array}\right\}
$$

where

$$
\begin{aligned}
& Z_{L}(n \omega)=\left|R+j n \omega_{e} L\right|=\sqrt{R^{2}+\left(j n \omega_{e} L\right)^{2}} \\
& \phi_{n}=\tan ^{-1} \frac{n \omega_{e} L}{R}
\end{aligned}
$$

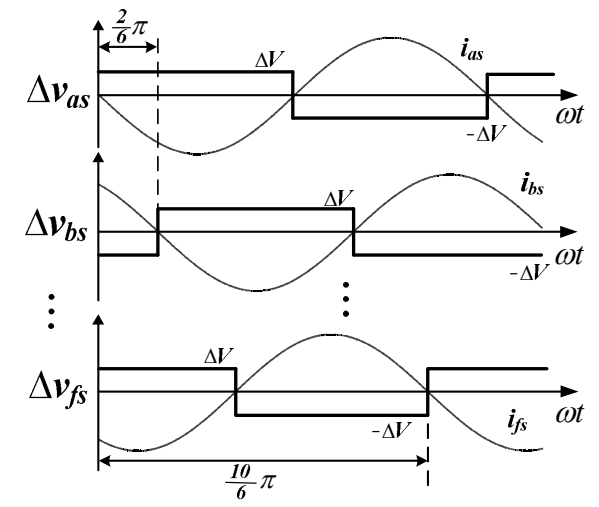

Fig. 9. Six phase currents and voltage errors of the IS-PMSM.

\section{PRoposed DEAD TIME COMPENSATION METHOD}

The phase currents have $6 n \pm 1$ and $6 n \pm 3$ harmonics as shown in (12). The $6 n \pm 1$ harmonics appears as $6 n$ harmonic ripple of the $d-q$ axis currents and also occurs in Y-connection machines. Thus, several literatures have already been proposed to eliminate these harmonics [4], [23]. On the other hand, the $6 n \pm 3$ harmonics occurs only in the independent phase machines. Therefore, this paper focuses on the compensation of the $6 n \pm 3$ current harmonics.

Assume the $3^{\text {rd }}, 9^{\text {th }}$ and $15^{\text {th }}$ harmonics are dominant among $6 n \pm 3$ harmonics. Then, the phase currents of the IS-PMSM can be expressed as (13).

$$
\begin{aligned}
i_{a s}= & -I_{m} \sin \omega t+I_{3} \sin 3 \omega t+I_{9} \sin 9 \omega t+I_{15} \sin 15 \omega t \\
i_{b s}= & -I_{m} \sin \left(\omega t-\frac{\pi}{3}\right)+I_{3} \sin 3\left(\omega t-\frac{\pi}{3}\right)+I_{9} \sin 9\left(\omega t-\frac{\pi}{3}\right) \\
& +I_{15} \sin 15\left(\omega t-\frac{\pi}{3}\right) \\
i_{c s}= & -I_{m} \sin \left(\omega t-\frac{2 \pi}{3}\right)+I_{3} \sin 3\left(\omega t-\frac{2 \pi}{3}\right)+I_{9} \sin 9\left(\omega t-\frac{2 \pi}{3}\right) \\
& +I_{15} \sin 15\left(\omega t-\frac{2 \pi}{3}\right) \\
i_{d s}= & -I_{m} \sin (\omega t-\pi)+I_{3} \sin 3(\omega t-\pi)+I_{9} \sin 9(\omega t-\pi) \\
& +I_{15} \sin 15(\omega t-\pi) \\
i_{e s}= & -I_{m} \sin \left(\omega t-\frac{4 \pi}{3}\right)+I_{3} \sin 3\left(\omega t-\frac{4 \pi}{3}\right)+I_{9} \sin 9\left(\omega t-\frac{4 \pi}{3}\right) \\
& +I_{15} \sin 15\left(\omega t-\frac{4 \pi}{3}\right) \\
i_{f s}= & -I_{m} \sin \left(\omega t-\frac{5 \pi}{3}\right)+I_{3} \sin 3\left(\omega t-\frac{5 \pi}{3}\right)+I_{9} \sin 9\left(\omega t-\frac{5 \pi}{3}\right) \\
& +I_{15} \sin 15\left(\omega t-\frac{5 \pi}{3}\right)
\end{aligned}
$$

where $I_{3}, I_{9}$ and $I_{15}$ are the magnitude of the $3^{\text {rd }}, 9^{\text {th }}$ and $15^{\text {th }}$ harmonics.

The phase currents can be transformed to the stationary reference frame as (15). 


$$
\begin{aligned}
i_{d s}^{s} & =\frac{1}{6}\left\{2 i_{a s}+i_{b s}-i_{c s}-2 i_{d s}-i_{e s}+i_{f s}\right\} \\
& =-I_{m} \sin \omega t \\
i_{q s}^{s} & =\frac{1}{2 \sqrt{3}}\left\{i_{b s}+i_{c s}-i_{e s}-i_{f s}\right\}=I_{m} \cos \omega t \\
i_{n s}^{s} & =\frac{1}{6}\left\{i_{a s}-i_{b s}+i_{c s}-i_{d s}+i_{e s}-i_{f s}\right\} \\
& =I_{3} \sin 3 \omega t+I_{9} \sin 9 \omega t+I_{15} \sin 15 \omega t
\end{aligned}
$$

Then (14) can be expressed as the synchronous reference frame like (15).

$$
\begin{aligned}
& i_{d s}^{e}=\cos \left(\omega_{e} t\right) i_{d s}^{s}+\sin \left(\omega_{e} t\right) i_{q s}^{s}=0 \\
& i_{q s}^{e}=-\sin \left(\omega_{e} t\right) i_{d s}^{s}+\cos \left(\omega_{e} t\right) i_{q s}^{s}=I_{m} \\
& i_{n s}^{e}=i_{n s}^{s}
\end{aligned}
$$

Equation (15) shows that the $6 n \pm 3$ current harmonics caused by dead time and turn-on/off time of the switching devices appears at the $n$-axis of the synchronous reference frame. Therefore, this current can be used for the dead time compensation of the IS-PMSM.

The flowchart of the proposed dead time compensation method is shown in Fig. 10. The sampled phase currents are transformed to the synchronous $d-q-n$ axis currents. The $n$-axis current which contains $6 n \pm 3$ harmonic components can be reduced to zero automatically by a PI current regulator. Then the distortion of phase currents caused by dead time can be reduced.

Fig. 11 shows the block diagram of the proposed dead time compensation method. There are three current regulators including $n$-axis. The $d-q-n$ voltage references are converted to the phase voltages to implement SPWM to each phase. By controlling the $n$-axis current to zero, the distortion of the phase currents caused by dead time can be reduced.

\section{SIMULATION}

The computer simulation of the proposed dead time compensation method is performed by using MATLAB simulink [24]. The rotor speed of the IS-PMSM is $100 \mathrm{rpm}$,

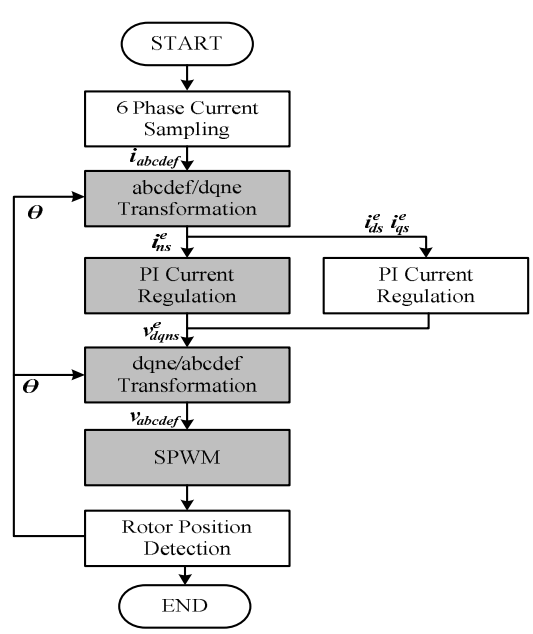

Fig. 10. Flowchart of the dead time compensation for ISPMSM.

TABLE III

MOTOR SPECIFICATION

\begin{tabular}{cccc}
\hline Rated Power & $2[\mathrm{~kW}]$ & Poles & 48 \\
Rated Current & $8[\mathrm{~A}]$ & Stator Resistance & $3[\Omega]$ \\
Rated Speed & $600[\mathrm{rpm}]$ & Stator Inductance & $13[\mathrm{mH}]$ \\
Max Speed & $1600[\mathrm{rpm}]$ & Torque Constant & $0.153[\mathrm{Nm} / \mathrm{A}]$ \\
\hline
\end{tabular}

the dead time is $2 \mu \mathrm{s}$ and the on-off time of the switching devices are $0.08 \mu s$ and $0.27 \mu s$, respectively. The specification of the implemented IS-PMSM is shown in Table III.

Fig. 12 shows the simulation results of the proposed dead time compensation method. The six-phase currents and n-axis current have $6 n \pm 3$ harmonics before the compensation as shown in Fig. 12(a) and (d). On the other hand, there is no distortion at the $d-q$ axis current as shown in Fig. 12(b) and (c). After the compensation, the n-axis current has no harmonics and the six-phase currents have pure sinusoidal waveform.

Fig. 13 shows the harmonic spectrum of the phase A current obtained from FFT. After the dead time compensation, the $6 n$ \pm 3 harmonics are effectively eliminated as shown in Fig. 13(b).

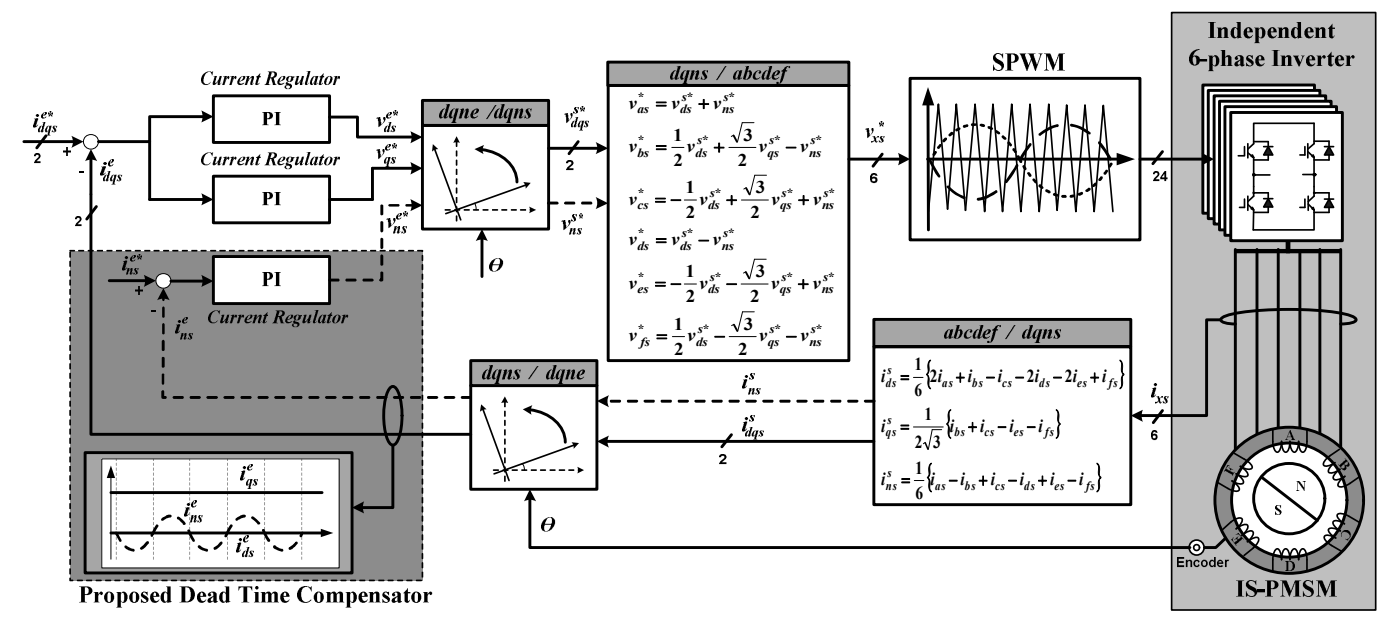

Fig. 11. Block diagram of the proposed dead time compensation algorithm. 


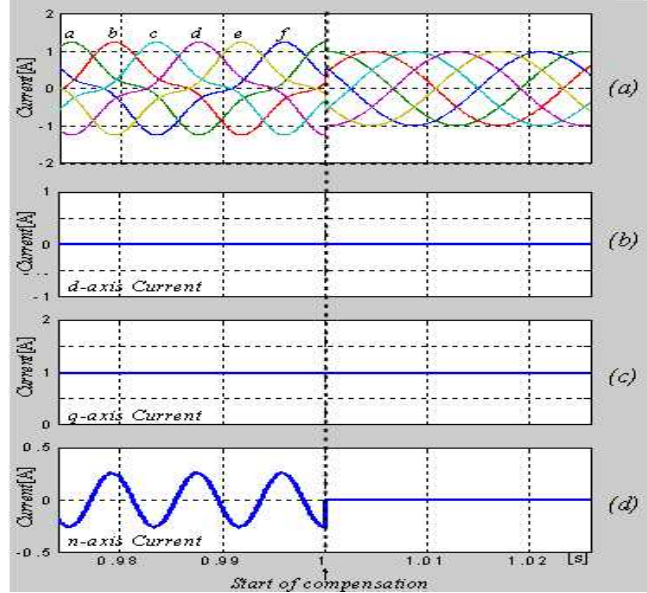

Fig. 12. Simulation results of the dead time compensation. (a) phase currents. (b) d-axis current. (c) q-axis current. (d) n-axis current

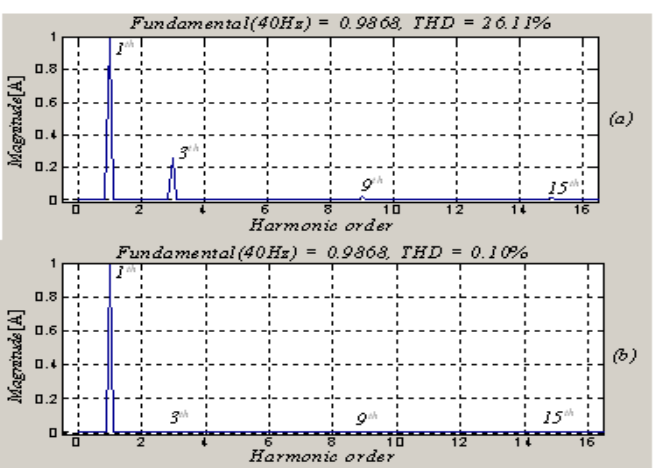

Fig. 13. The harmonic spectrum of the phase A current. (a) Before compensation. (b) After compensation,

\section{SIMULATION}

The proposed dead time compensation method is implemented to $2 \mathrm{~kW}$ IS-PMSM. The specification of the IS-PMSM is shown in Table III. The entire drive system is controlled by digital signal processor (DSP) TMS320VC33 and field-programmable gate array (FPGA). The sampling period of the current regulator is $100 \mu \mathrm{s}$ and the PWM switching frequency is $5 \mathrm{kHz}$. The dead time is configured at 2 $\mu s$ and the turn-on/off times of the switching devices are 0.08 $\mu s$ and $0.27 \mu s$, respectively. Before the dead time compensation, these harmonics appears only at the n-axis current as shown in Fig. 14. After the compensation, the $n$-axis current harmonics are eliminated and the phase currents have pure sinusoidal waveforms. However, there are no harmonics in the $d$ - $q$ axis currents before and after the compensation.

Fig. 15 show the stationary $d-q-n$ axis currents and Lissajous circles. As shown in Fig. 15(a), the harmonic components appear at the stationary $n$-axis current. Thus the Lissajous figure of the stationary $d-q$ axis currents is perfectly circular shape as shown in Fig. 15(b). On the other hand, the distorted Lissajous shape of the stationary $d-q-n$ axis currents before the compensation becomes circular after the compensation as shown in Fig. 15(c).

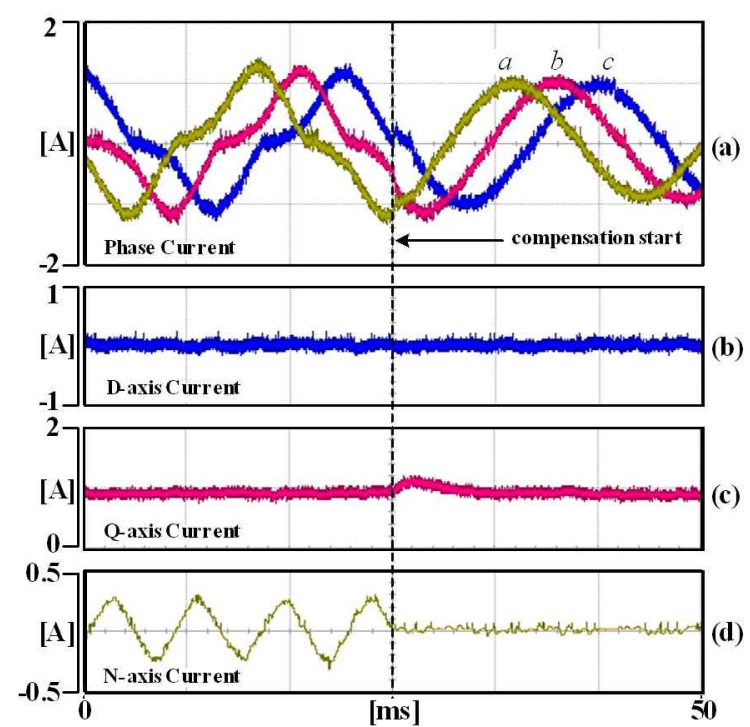

Fig. 14. Experimental results of the dead time compensation. (a) phase currents. (b) d-axis current. (c) q-axis current. (d) n-axis current.

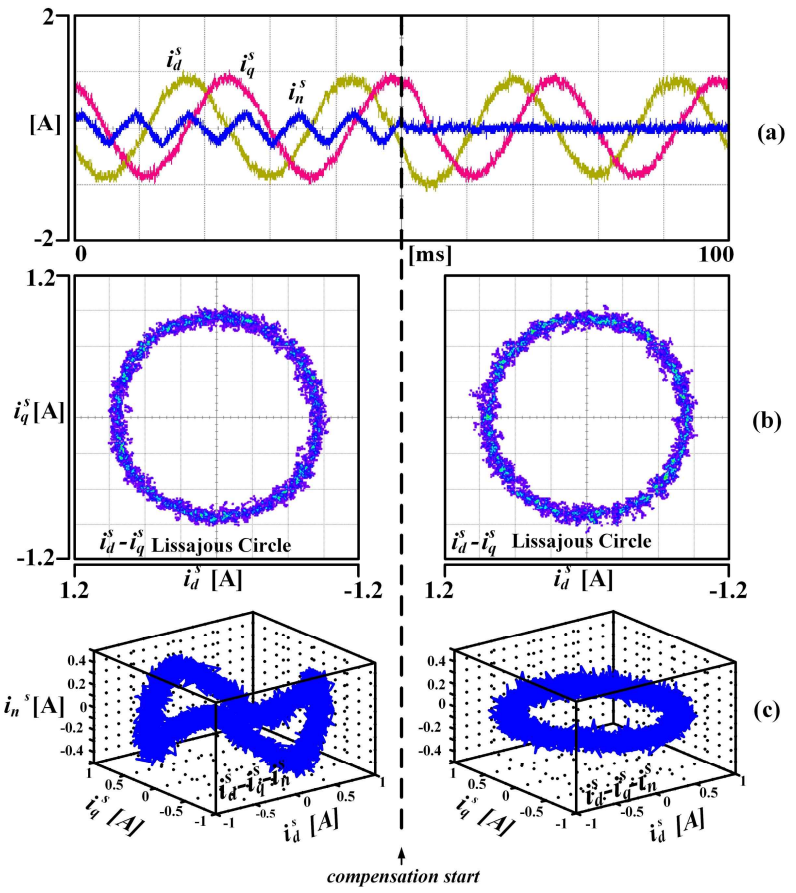

Fig. 15. Comparison of the stationary $d-q-n$ axis currents before and after compensation. (a) Stationary $d-q-n$ axis currents. (b) Lissajous circle of the stationary $d-q$ axis currents. (c) Lissajous shape of the stationary $d-q-n$ axis currents.

Fig. 16 shows the spectrum of the phase A current. Before the compensation, the phase A current has $3^{\text {rd }}$ harmonic component dominantly; after the compensation, only the fundamental component is exist. These results show that the distorted currents and output voltages of the H-bridge inverter due to the dead time and the nonlinear characteristics of the switching elements can be compensated by using the proposed method. 

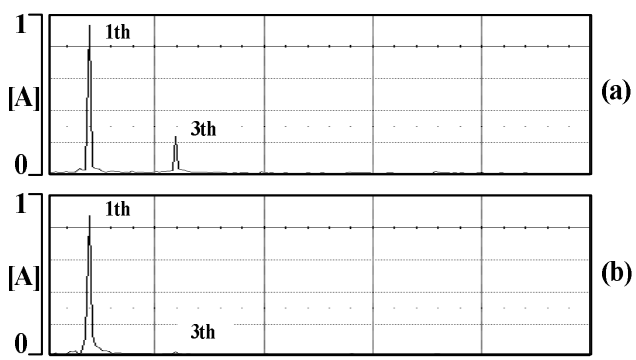

Fig. 16. FFT results of the phase A current. (a) Before compensation. (b) After compensation.

\section{CONCLUSIONS}

This paper proposes the vector control method based on a multiple $d-q-n$ spaces concept for IS-PMSM and the dead-time compensation algorithm by using the n-axis current as a reference signal for the compensation. The current harmonics caused by dead time and the nonlinearity of the switching devices were analyzed mathematically and effectively eliminated by controlling the $n$-axis current to zero.

This algorithm does not require any additional hardware and the other information except phase current and rotor position for reference frame transformation. Moreover, this method can be easily implemented without complicated mathematical calculation and off-line experimental measurements. The feasibility and effectiveness of the proposed algorithm were verified through the computer simulation and experiments.

\section{ACKNOWLEDGMENT}

This work was supported by the National Research Foundation of Korea(NRF) grant funded by the Korea government. (No. 2012026153)

\section{REFERENCES}

[1] P. Zhao and G. Yang, "Torque density improvement of five-phase pmsm drive for electric vehicles applications," Journal of Power Electronics, Vol. 11, No. 4, pp. 401-407, Jul. 2011.

[2] G. K. Singh, "Multi-phase induction machine drive research a survey," Electric Power Systems Res, Vol. 62, pp. 139-147, 2002.

[3] R. Bojoi, F. Farina, A. Tenconi, and F. Profumo, "Analysis of the asymmetrical operation of dual three-phase induction machines," Conf. Rec. IEEE IEMDC, pp. 429-435, 2003.

[4] R. Bojoi, A. Tenconi, and F. Profumo: "Digital synchronous frame current regulation for dual-three phase induction motor drives," Conf. Rec. IEEE PESC, pp. 1475-1480, 2003.

[5] T. Gopalarathnam, S. Waikar, H. A. Toliyat, M. S. Arefeen, J. C. Moreira, "Development of low cost multi-phase brushless permanent magnet (BPM) motors with unipolar current excitations", Proceedings of the IEEE-IAS 1999 Annual Meeting, Phoenix, AZ, Oct. 3-7,
1999, pp. 173-179, 1999.

[6] Y. Murai, T. Watanabe, and H. Iwasaki, "Waveform distortion and correction circuit for PWM inverters with switching lag-times," IEEE Trans. Ind. Appl., Vol. IA-23, No. 5, pp. 881-886, Sep./Oct. 1987.

[7] S. G. jeong and M. H. Park, "The analysis and compensation of deadtime effects in PWM inverters," IEEE Trans. Ind. Electron., Vol. 38, No. 2, pp. 108-114, Apr. 1991.

[8] D. Leggate and R. Kerkman, "Pulse-based dead-time compensator for PWM voltage inverters," IEEE Trans. Ind. Electron., Vol. 38, No. 2, pp. 191-197, Apr. 1997.

[9] J. W. Choi and S.-K. Sul, "Inverter output voltage synthesis using novel dead time compensation," IEEE Trans. Power Electron., Vol. 11, No. 2, pp. 221-227, Mar. 1996.

[10] T. Sukegawa, K. Mizuno, T. Matsui, and T. Okuyama, "Fully digital, vector controlled PWM VSI-fed ac drives with an inverter dead-time compensation strategy," IEEE Trans. Ind. Appl., Vol. 27, No. 3, pp. 552-559, May/Jun., 1991.

[11] H. Zhao, Q. M. J. Wu, and A. Kawamura, "An accurate approach of nonlinearity compensation for VSI inverter output voltage," IEEE Trans. Power Electron., Vol. 19, No. 14, pp. 1029-1035, Jul. 2004.

[12] A. Cichowski and J. Nieznanski, "Self-tuning dead-time compensation method for voltage-source inverters," IEEE Power Electronics. Letter, Vol. 3, No. 2, pp. 72-75, Jun. 2005.

[13] S. Sayeef and M. F. Rahman, "Improved flux and torque estimators of a direct torque controlled interior PM machine with compensations for dead-time effects and forward voltage drops," Journal of Power Electronics, Vol. 9, No. 3, pp. 438-446, May 2009.

[14] A. R. Munoz and T. A. Lipo, "On-line dead-time compensation technique for open-loop PWM-VSI drives," IEEE Trans. Power Electron., Vol. 14, No. 4, pp. 683-689, Jul. 1999.

[15] H. S. Kim, H. T. Moon, and M. J. Youn, "On-line dead-time compensation method using disturbance observer," IEEE Trans. Power Electron., Vol. 18, No. 6, pp. 1336-1345, Nov. 2003

[16] N. Urasaki, T. Senjyu, K. Uezato, and T. Funabashi, "Adaptive dead-time compensation strategy for permanent magnet synchronous motor drive," IEEE Trans. Energy Convers., Vol. 22, No. 2, pp. 271-280, Jun. 2007.

[17] K. R. Cho and J. K. Seok, "Inverter nonliearity compensation in the presence of current measurement errors and switching device parameter uncertainties," IEEE Trans. Power Electron., Vol. 22, No. 2, pp. 576-583, Mar. 2007.

[18] H. M. Ryu, J. H. Kim, and S.K. Sul, "Analysis of multiphase space vector pulse-width modulation based on multiple d-q spaces concept", IEEE Trans. Power Electron., Vol. 20, No. 6, pp. 1364-1371, Nov. 2005.

[19] H. M. Ryu and S. K. Sul, "Multiple d-q Spaces Concept for Multi-Phase AC Motor Drive," ICPE(ISPE), pp. 670-674, 2004.

[20] J. Holz, "Pulsewidth Modulation-A Survey," IEEE Trans. Industrial Electron., Vol.39, No.5, pp.410-420, Dec. 1992

[21] H. W. Van der Broeck, and H. C. Skudelny, "Analysis and realization of a pulsewidth modulator based on voltage space vectors," IEEE Trans. Ind. Appl., Vol.24, pp.142-150, Jan. /Feb. 1988. 
[22] P. Khluabwannarat. C. Thammarat, S. Tadsuan, and S. Bunjongjit, "An analysis of iron loss supplied by sinusoidal, square wave, bipolar PWM inverter and unipolar PWM inverter," in IPEC 2007, pp. 1185-1190, 2007.

[23] S. H. Hwang and J. M. Kim, "Dead time compensation method for voltage-fed pwm inverter," IEEE Trans. Energy Convers., Vol. 25, No. 1, pp 1-10, Mar. 2010.

[24] SIMULINK Model Based and System Based Design, The Math Works Inc., Natick, MA, 2002.

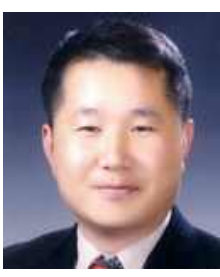

Ouk-Sang Park received the B.S and M.S degrees in electrical engineering from Dong-A University, Busan, Korea, in 1991 and 1994, respectively. He was a Research and Development Engineer of the recyclable energy of solar power plant in Ssang Yong Heavy Industries. He is with STX Engine as a Senior Design Engineer of the naval propulsion system. His research interests include the noise suppression drive technology.

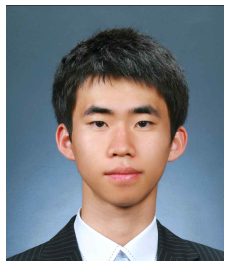

Je-Wook Park received the B.S. and M.S. degrees in electrical engineering from Pusan National University, Busan, Korea, in 2007 and 2009, respectively. $\mathrm{He}$ is currently working toward the Ph.D. degree at Pusan National University. His research interests include power conversion, electric machine drives and electric vehicle.

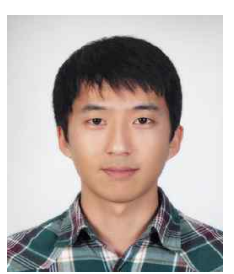

Chae-Bong Bae received the B.S. degree from Hanbat National University in 2006, and the M.S. degree in electrical engineering from Pusan National University, Busan, Korea, in 2010. He is currently a Research Engineer with LSIS. His research interests include power conversion and electric machine drives.

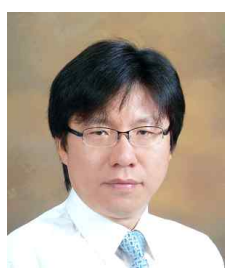

Jang-Mok Kim received the B.S. from Pusan National University, Korea, in 1988, and the M.S. and Ph.D. degrees from the Department of Electrical Engineering, Seoul National University, Seoul, Korea, in 1991 and 1996, respectively. From 1997 to 2000, he was a Senior Research Engineer with the Korea Electrical Power Research Institute (KEPRI). Since 2001, he has been with the School of Electrical Engineering, Pusan National University, where he is currently a Research Member with the Research Institute of Computer Information and Communication, a Faculty Member, and a head of LG Electronics Smart Control Center. As a Visiting Scholar, he joined the Center for Advanced Power Systems (CAPS), Florida State University, in 2007. His research interests include the control of electric machines, electric vehicle propulsion, and power quality. 